\title{
Las resoluciones penales ultra petita, para la protección de los derechos fundamentales en el Código Nacional de procedimientos penales
}

\section{José Luis Anaya Ríos Miguel Ángel Anaya Ríos Ignacio García Páez}

Recibido: 8 de Junio

Dictaminado: 02 de Septiembre

\section{Resumen}

La función jurisdiccional ha sufrido cambios jurídicos trascendentales, como lo es en materia penal, en la cual se pondera la suplencia de la queja, en este sentido, la ley pierde permanencia temporal, espacial y validez en las normas constitucionales, leyes generales y locales en las cuales se adicionan, reforman y derogan, armonizando a los derechos humanos a través de los principios como el de interpretación, de legalidad, del debido acceso a la justicia, de presunción de inocencia, del debido proceso entre otros, teniendo como premisa mayor la dignidad humana.

Palabras clave: Resoluciones Ultra petita, Actividad Jurisdiccional, Derechos Humanos y Fundamentales.

\section{The ultra petita criminal resolutions for the protection of fundamental rights in national code of criminal procedures}

\begin{abstract}
The jurisdictional function has undergone transcendental legal changes, as it is in criminal matters, in which the substitution of the complaint is considered, in this sense, the law loses temporary, spatial and validity in constitutional norms, general laws and in which they
\end{abstract}

Universidad Autónoma de Nayarit (México). luisanayarios@hotmail.com Universidad Autónoma de Nayarit (México). miguelanaya2000@hotmail.com Universidad Atónoma de Nayarit (México). Ignacio_paez_tepic@hotmail.com 
are added, reformed and repealed, harmonizing human rights through principles such as interpretation, legality, due access to justice, presumption of innocence, due process among others, based on the premise the greater the human dignity.

Key words: Resolutions Ultra petita, Jurisdictional Activity, Human Rights and Fundamental.

\section{Sumario}

I Introducción; II Naturaleza y aplicación de la regla Ultra Petita; III Uso moderador de la Ultra Petita en diversas ramas del derecho; IV La congruencia legal, el protagonismo judicial y resoluciones Ultra Petita; V Conclusiones; Bibliografía

\section{Introducción}

En la actualidad la figura del Ministerio Público tiene la atribución de ejercitar acción penal una vez que cumpla con los extremos de la norma, o bien pedir el procedimiento abreviado, solicitar a la autoridad jurisdiccional imponga al acusado determinada pena o medida de seguridad, facultad por cierto propia y exclusiva; debiendo adecuar su juicio y ajustar su análisis de la autoría y participación, las agravantes o atenuantes del caso concreto, la tentativa, la calidad especifica del autor, el concurso real e ideal, la reincidencia, la pluralidad de sujetos, las circunstancias de tiempo, modo y lugar, para cumplir con la exigencia hecha, a menos que se trate de una pena menor, de lo cual se dará cuenta mediante el recurso respectivo.

Con el activismo judicial, el juzgador dejará de ser un mero espectador y tomara el control del proceso, y de ser necesario podrá imponer sanciones más altas que las solicitadas por el Fiscal, enmendando el error o agravando, la cuantía de la reparación del daño, ordenando prácticas de diligencias a fin de conocer mejor los hechos, dictando resoluciones interpretativas que comprenda obligaciones de hacer o dejar de hacer a otros sujetos no intervinientes, adecuando el caso a la realidad, siempre y cuando los hechos no se modifiquen y se protejan los derechos fundamentales, es por ello que la función jurisdiccional es esencial para aspirar a la justicia que tanto anhela la sociedad. 


\section{Naturaleza y aplicación de la regla ultra petita}

El antepuesto latino ultra, significa más allá. ${ }^{1}$ El Diccionario Jurídico Espasa, define al término en estudio como incongruencia en la sentencia que concede más de lo pedido. ${ }^{2}$

Petita, se refiere al infinitivo pedir; al conjuntarlos significaría dar más allá de lo pedido; por tanto, éste compuesto aplicado al derecho procesal penal, significaría que el juez otorga más de lo pretendido por las partes, afectando con su exceso a alguna de ellas o incluso a un tercero ajeno a la litis. ${ }^{3}$

Díaz de León, hace referencia a la resolución del juez, normalmente la sentencia final que concede más o va más allá de lo que las partes le pidieron o pretendieron. (Díaz de León, 1989: 2191)

Ésta frase ha sido utilizada en las determinaciones de la Suprema Corte de Justicia de la Nación (en adelante SCJN) y se refiere a la prohibición del órgano jurisdiccional de extenderse ha hechos que no han sido materia del debate; un ejemplo lo encontramos en la tesis aislada identificada al rubro: "SENTENCIA INCONGRUENTE POR EXCESO DE PODER."

Por su parte la Primera Sala en una tesis aislada un poco mas reciente que la anterior, se expresó respecto a la apelación como litis abierta en la que el A Quo si puede resolver cuestiones que no le fueron planteadas, condicionada también a que se resolvieran todos los puntos que le fueron planteados por las partes, según se desprende del rubro identificado: APELACION PENAL. ${ }^{5}$

El principio procesal que antagoniza con la figura procesal ultra petita, es el de congruencia que se constituye como su contrario natural, y se refiere a que al resolverse una controversia se haga atendiendo a lo planteado por las partes,

1 Real Academia Española, http://dle.rae.es/?id=b2QZCEO. Consulta realizada el 23 de mayo de 2017.

2 Diccionario jurídico ESPASA, (e) siglo XXI, s.e. España, Espasa Calpe S.A., 2002, p. 1407.

$3 \mathrm{La}$ idea es que el órgano jurisdiccional extienda los efectos de sus resoluciones, condenando a la reparación de daño y dentro del mismo proceso, no en el civil, a los terceros obligados, que se enlistan en el artículo 68 del Código Penal para el Estado de Nayarit, como los ascendientes, tutores, directores de talleres; Las personas físicas o jurídico-colectivas, las personas jurídico-colectivas, El Estado, los municipios y organismos descentralizados subsidiariamente.

4 Semanario Judicial de la Federación, Quinta Época, Tercera Sala, Tomo CXXVI, Pág. 629.

5 Tesis publicada en el Semanario Judicial de la Federación Sexta Época, Primera Sala, volumen LXXIV, segunda parte, 8 de agosto de 1963, p. 14. 
sin omitir nada ni añadir cuestiones no hechas valer, ni contener consideraciones contrarias entre sí o con los puntos resolutivos. ${ }^{6}$

La corriente que contrapesa al principio de congruencia, es el activismo judicial, que significa en esencia que el juez no solo estudie de forma enunciada las declaraciones de los testigos, victima u ofendido, del indiciado, dictámenes periciales, informes policiales e inspecciones ministeriales; sino que pueda separarse de su ámbito de confort, para acudir al lugar de los hechos, y verificar por sí mismo como se encuentran las cosas, objetos, personas, animales o bienes, que le permitan ilustrarse de una mejor manera y emitir una resolución, con pena o medida de seguridad mayor a la solicitada y apegada a la realidad.

A este protagonismo del juez se le ha denominado: Activismo judicial; Expansión judicial; judicialización de la política; ${ }^{7}$ (Fix, 1999: 170) politización de la justicia, juridificación, justicia constitucional, modelo de juez estructural, gobierno de los jueces, protagonismo judicial, judiciocracia. (Manili, 2011: 137)

En el ámbito aplicativo se trata, según Zagrebelsky de que “...el legislador debe resignarse a ver sus leyes tratadas como partes del derecho, y no como todo el derecho. Pero puede pretender de los jueces que se mantengan abiertas las posibilidades de ejercitar su derecho a contribuir políticamente a la formación del ordenamiento jurídico" (Zagrebelsky, 2008: 153)

Es precisamente a la nueva clase de funcionarios judiciales, a quienes, en un ámbito de ética profesional, institucional y basada en el saber jurídico administren justicia, fijando los parámetros por el que se ha de regir la conducta humana, y al mismo tiempo se legitimen democráticamente como un poder del Estado.

El dilema se centra en establecer el rol del Juez, sea como director o solo como espectador del procedimiento penal. El tema resulta de mucha importancia para los actores jurídicos, ya que desde los albores de la Constitución escrita, el papel del juez fue la de participar activamente de la ley y no solo la de sujetarse pasivamente a su mandato; así encontramos un primer antecedente en el caso Wiliam Marbury vs James Madison, resuelto en el año de 1803, por el jefe de

6 I.1o.A. J/9, Semanario Judicial de la Federación y su Gaceta, Novena Época, Tribunales Colegiados de Circuito, Tomo VIII, agosto de 1998, Pág. 764.

7 Fix Zamudio, Héctor, El Poder Judicial, Revista Jurídica UNAM, México, Instituto de Investigaciones Jurídicas, Serie Doctrina Jurídica, num. 3, 1999, p. 170. 
Justicia Jhon Marshall; éste último por cierto causante del problema en el año de 1881, cuando ostentaba el cargo de Secretario de Gobierno de Los Estados Unidos de Norteamérica bajo el mandato de Jhon Adams y como si se tratase de un boomerang se le regresó el caso para resolverlo, al jurar su nuevo cargo de Jefe de Justicia. ${ }^{8}$

En efecto, en dicha sentencia sentó las bases del derecho constitucional y del derecho procesal constitucional, tales como la supremacía constitucional, el control de constitucionalidad, el principio de legalidad, la interpretación constitucional, los poderes limitados de los órganos creados por la carta magna, el control de constitucionalidad de oficio, la diferencia entre actos reglados y discrecionales de los poderes públicos, el efecto limitado de las sentencias que declaran la inconstitucionalidad de una norma en un sistema de control difuso, los remedios procesales existentes para reparar violaciones de derechos protegidos por la constitución (hoy llamados procesos constitucionales), los mandamientos de ejecución dirigidos por el poder judicial a los funcionarios públicos, la operatividad de las normas constitucionales, el juramento que prestan los funcionarios públicos. (Klanili, 2011: XIII)

No obstante la relevancia del tema, constitucional, ya doscientos años atrás, existían funciones activista de parte de los jueces; tal es el caso del Juez Inglés Sir Edward Coke, quien en 1610 al resolver el caso conocido como el Dr. Thomas Bonham's Case, creó la técnica de la judicial review en el common law considerándolo un derecho superior sobre las leyes; al decidir interpretar la autoridad del rey desde dos vertientes, señalando que el Royal Charter $^{9}$ del Colegio de Médicos, solo sancionaba la mala práctica de la medicina y no la

\footnotetext{
$8 \mathrm{Al}$ no entregarle la noche anterior a la conclusión del Gobierno (como si lo hizo con la mayoría de los 42 nombramientos), el nombramiento de Juez de Paz a William Marbury, quien posteriormente lo reclama a James Madison, como Secretario de Gobierno entrante bajo el mandato de Thomas Jefferson. Véase al respecto Andrade María Virginia, Sentencia Marbury versus Madison (1803), Derecho y Sociedad Revista de Estudiantes de Derecho de la Universidad Monteávila/Universidad Monteávila, Facultad de Ciencias Jurídicas y Políticas, ed. Altolitho, Caracas, abril 2003, núm. 4. pp. 273-279.

9 Concesión monopolizada otorgada en 1518, por el Rey Enrique VIII, al Colegio de Médicos de Inglaterra para la formación de médicos del nuevo tipo humanista, otorgándole poderes para expedir licencias, sancionar el ejercicio de la medicina y/o la mala praxis. Sus requisitos de ingreso eran tan exigentes que a un siglo de si fundación solo habían expedido 24 licencias. Véase a Martínez Fernando Rey, Reflexiones sobre una sentencia bicentenaria, ed. Porrúa, México 2011, s.e. p. XIII. pp. 1 a 21.
} 
practica ilícita de la misma, por ende la primera debía sancionarse con prisión y la segunda solo con multa; en esta última situación se encontraba el Doctor Bonham's quien ejerció la medicina sin licencia y fue encarcelado en la prisión de Newgate.

La anterior decisión abrió la puerta al Juez Coke para fallar en contra de otro monopolio regio ${ }^{10}$ (Martínez, 2011: XIII) y más tarde sostuvo que todas las leyes del reino contrarias a las leyes del mismo reino, serían nulas y no tendrían efecto, limitando así a la corona y al parlamento.

¿Cómo entonces, si desde antes que existieran la Constitución, ya existían pronunciamientos judiciales que se salían de una mera interpretación a la ley, para exponer mediante un análisis, los principios de legalidad, la revisión judicial y el de la controversia constitucional? ¿hoy, a cuatrocientos años de distancia no se les da mérito a los jueces para utilizar su criterio, con el fin de encontrar la verdad de los hechos e imponer penas que pudieran rebasar la petitio de las partes?

Por reforma constitucional de 18 de junio de 2008, se amplió el espectro garantista de los jueces de primera instancia, al ser ellos quienes mediante sus resoluciones pueden ejercer el control difuso de constitucionalidad, que consiste en la prevalencia de las normas fundamentales de derecho humanos sobre aquellas normas que la contravengan.

Así es como los jueces podrán tener peso dentro del poder del Estado, que se pueden manifestar políticamente mediante sus resoluciones con consecuencias políticas $^{11}$ que repercutan en la sociedad y sobre los demás poderes, sea interpretando, aplicando o invalidando la norma jurídica, hasta llegar a ser el interprete final de la constitución que aumenta el carácter político de sus sentencias. (Manili, 2011: 138) Que quizás no solo se limiten a resolver el caso concreto, sino a resolver los sistemas sociales como la educación, la seguridad

\footnotetext{
10 El common pleas fallo que, aunque la Corporación de Sastres de Ipswich, tenía concedida la autoridad por una Charter del Rey, de impedir que ningún otro sastre se instalara en la localidad sin su aprobación, el common law no permitiría que se prohibiera comerciar libremente a una persona y por tanto amparó al sastre que se había instalado sin su autorización.

11 La política entendida como ciencia, es decir el ejercicio de poder o el arte de conducir un pueblo o un país, eso es lo que hoy en día algunos denominan política arquitectónica, es decir al que apunta a la construcción y conducción de un Estado; no a la lucha o combate de individuos o grupos para utilizar el poder que los vencedores usarían en su provecho.
} 
jurídica, la economía, la cultura, la tenencia de la tierra, la igualdad, los derechos civiles y políticos, entre otras y expandiendo incluso el espacio de intervención sobre la política de la cual no puede prescindir.

Mediante sentencias de mandamiento como una opción ante las declarativas, constitutivas y de condena; el juez podría dar las ordenes necesarias para que el conflicto no quedase sin resolver; así por ejemplo, no solo decidir respecto a la culpabilidad y la reparación del daño, sino también tomar otras medidas, para que el delito no se repita en agravio del propio ofendido o de futuros terceros que resultaran ofendidos por el mismo acto ilícito dañino; así por ejemplo, mandar que se coloquen avisos de peligro y una malla ciclónica en una subestación eléctrica que ocasionó la muerte de un menor.

El activismo judicial implicaría que el órgano jurisdiccional, desahogue a su arbitrio diligencias no solicitadas por las partes para conocer los hechos para estar en condiciones de emitir sentencias justas, como pudiera ser el conocer la opinión de un perito en psiquiatría ante el dictamen de médico legista general que dictamina sobre el estado mental del sujeto activo; ante el ofrecimiento de un acta de defunción del indiciado que traería como consecuencia la conclusión anormal del procedimiento, ${ }^{12}$ solicitar al Oficial del Registro Civil el informe o acta correspondiente que le permita comprobar la aseveración; practicar la inspección o reconstrucción de los hechos; ante algún indicio de duda, solicitar la confronta de huellas y firmas de las partes en documentos públicos y privados.

Asimismo, ante la pretensión del Ministerio Público para que se condene al imputado a la reparación material por el delito de robo de un vehículo del servicio público de taxi, además, el juez emite sentencia por el pago de perjuicios, que los hace consistir en las ganancias diarias que dejó de generar dicho vehículo con motivo de un servicio suspendido y el pago de los salarios que dejó de percibir el chofer en su calidad de víctima; excediéndose con ello en las prestaciones reclamadas, al mismo tiempo que resuelve el caso completamente.

En el caso del delito de abandono de familiares; el juez no solo debe

12 El artículo 130 del CPEN, establece que la muerte del delincuente extingue la sanción penal, así como las sanciones que se hubieren impuesto, a excepción de la responsabilidad civil, la de decomiso de los instrumentos con que se cometió el delito y de las cosas que sean efecto u objeto de él, salvo las excepciones que establezcan las leyes. 
condenar por los alimentos que se sucedieron antes del año a la presentación de la querella, sino que, podrá ir más allá de lo pedido actualizando las prestaciones a la fecha de la sentencia. ${ }^{13}$

En el ámbito internacional, la imposición de una pena superior a la requerida por el acusador fue reseñada en el área penal de la Defensoría Oficial ante la Corte Suprema de Justicia de la Nación de Argentina, mediante un fallo jurisprudencial, también conocida como "El precedente "Galíndez" del año 1957.

En dicho caso, la parte recurrente había cuestionado la facultad de los jueces para imponer sanciones de mayor gravedad que las solicitadas por el Agente Fiscal en su respectivo requerimiento. Para tales fines se valió de los precedentes de Fallos, 234:270 y 234:367 en los cuales, el máximo Tribunal había descalificado dos sentencias de Cámara que habían agravado la situación del imputado pese a no existir un recurso fiscal que la habilitara para ello (proscripción de la reformatio in pejus).

En este sentido, el Tribunal sentó los criterios que defiende la imposición de una pena mayor a la solicitada por el Fiscal:

1.- En cuanto a la pena se sostiene que tanto el monto como la modalidad de su ejecución son poderes discrecionales de los jueces.

2.- Cualquiera que sea la calificación jurídica que en definitiva efectúen los jueces.

3.- Los magistrados sentenciantes no se encuentran limitados por la subsunción jurídica propuesta por el acusador.

4.- El juez o tribunal que aplica una determinada figura delictiva distinta a la pedida por el representante del Ministerio Público, no contraviene ni vulnera el principio de congruencia, ni por ende, tampoco lastima el derecho de defensa.

5.- En autos, el imputado ha podido saber cuál era el hecho, el objeto de la acusación y las pruebas que la sustentaban, por lo que la cuantificación de la pena a aplicar en el caso concreto, más allá de que difiera de la pedida por el Ministerio Fiscal, no es violatoria del derecho de defensa, ni del debido proceso legal.

13 Segundo párrafo del artículo 206 del CNPP, que establece: No podrá imponerse una pena distinta o de mayor alcance a la que fue solicitada por el Ministerio Público y aceptada por el acusado. 
6.- Nada obsta a que el juez de primera instancia pueda aplicar una pena mayor a la solicitada por el Fiscal, o modificar la calificación jurídica que aquél pretendiera, toda vez que en virtud de la regla iura novit curia sólo se encuentra subordinado a los hechos incluidos en la acusación. ${ }^{14}$

A final de cuentas, se debe resolver el conflicto social, no dejarlo latente, evitar la inutilidad del proceso, que interese la denominación que se le dé a la demanda, sino los hechos y las pretensiones; luego entonces, carecería de todo sentido de justicia y de lógica jurídica, que estando los hechos probados y reconocidos el derecho que le asiste al actor, se desestime la demanda, no lográndose con ello el fin supremo del proceso, que es la justicia.

\section{Uso moderador de la Ultra petita en diversas ramas del derecho}

Resolver más allá de lo pedido, se ha venido aplicando en otras materias jurídicas; así en el artículo 79 de la Ley de Amparo vigente, se establece la suplencia de la deficiencia de los conceptos de violación o agravios; por ejemplo, en favor de los menores o incapaces o aquellos casos en que se afecte el orden y desarrollo de la familia; a favor del inculpado, sentenciado y ofendido; a favor de los ejidatario y comuneros cuando se afecten sus bienes y derechos agrarios; a favor del trabajador, a favor de quienes por sus condiciones de pobreza, marginación se encuentren en clara desventaja en la defensa de un juicio en general en otras materias cuando se advierta que en contra del quejoso ha habido una violación evidente de la ley que lo ha dejado sin defensa por afectar sus garantías individuales.

En Materia laboral la Junta de Conciliación y Arbitraje podrá requerir al trabajador cuando la demanda del trabajador sea incompleta, en cuanto a que no comprenda todas las prestaciones que de acuerdo con esta Ley deriven de la acción intentada o procedente, conforme a los hechos expuestos por el trabajador,

14 http://www.eft.com.ar/doctrina/articulos/notaalfallo.htm 
la Junta, en el momento de admitir la demanda, subsanará ésta. ${ }^{15}$

En un juicio civil o laboral en el que no se han reclamado el pago de gastos y costas en favor del abogado del actor, el Juez deberá acordar de oficio, por tratarse de un derecho social, aún solo cuando no se haya solicitado, al no existir razón que justifique la exclusión de los profesionales del derecho que ejercen libremente su profesión de recibir su salario y también independientemente de los recursos para hacerlos valer, según lo estipulado en el artículo 123 fracción VI de la CPEUM. ${ }^{16} \mathrm{Al}$ tratarse de un derecho disponible, el no hacerlo afectaría el orden público ya que se trata de un derecho irrenunciable. ${ }^{17}$

En materia mercantil encontramos una tesis aislada que estipula la aplicación ultra petitia, según se visualiza en la resolución emitida por el Segundo Tribunal Colegiado en Materia Civil del Sexto Circuito, bajo el índice del Libro XXIV, septiembre de 2013, Tomo 3, Pag. 2642 con el rubro:

PRESCRIPCIÓN DE LA EJECUCIÓN DE LA SENTENCIA EN MATERIA MERCANTIL. EL JUEZ PUEDE ANALIZARLA DE MANERA OFICIOSA, SIN QUE CON ELLO SE VULNEREN LOS PRINCIPIOS DE CONGRUENCIA Y DISPOSITIVO QUE RIGEN ESE PROCEDIMIENTO.

En los asuntos de familia, el juez podrá fallar ultra petita y extra petita, cuando sea necesario para brindarle protección adecuada a la pareja, al niño, la niña o adolescente, a la persona con discapacidad mental o de la tercera edad, y prevenir controversias futuras de la misma índole. (Cordoba, 2015: 74)

En materia agraria, se pronunció el VIII Congreso Mexicano de Derecho

15 Segundo párrafo del artículo 685 de la LFT

16 Los salarios mínimos que deberán disfrutar los trabajadores serán generales o profesionales. Los primeros regirán en las áreas geográficas que se determinen; los segundos se aplicarán en ramas determinadas de la actividad económica o en profesiones, oficios o trabajos especiales.

Los salarios mínimos generales deberán ser suficientes para satisfacer las necesidades normales de un jefe de familia, en el orden material, social y cultural, y para proveer a la educación obligatoria de los hijos. Los salarios mínimos profesionales se fijarán considerando, además, las condiciones de las distintas actividades económicas. 17 Tribunal Supremo de Justicia de la República Bolivariana de Venezuela, Juzgado Accidental de Primera Instancia en lo Civil, Mercantil, Agrario, Del Tránsito y Bancario de la Circunscripción Judicial del Estado Amazonas, con sede en Puerto Ayacucho, a los 31 días del mes de octubre de dos mil seis (2006). Visible en la página electrónica http://amazonas.tsj.gob.ve/decisiones/2006/octubre/337-31-03-5924-.html. Consulta realizada el 25 de junio de 2015. 
Procesal, en 1980 cuando planteó como una de sus conclusiones que: La justicia social agraria debe regularse con base a los principios generales del Derecho Procesal y especialmente en aquellos que responden a las peculiares necesidades de dicha justicia. Será gratuita, oral, acelerada, inquisitiva en materia de pruebas, con libre valorización de pruebas, accesible a todas las personas, con adecuada protección a los débiles y pobres, con absoluta publicidad y humanizada en el máximo posible, con igualdad y oportunidades de defensa y buenos jueces para todos. ${ }^{18}$

En el ocaso del Código de Procedimientos Penales para el Estado de Nayarit, se observan normas que le permiten al juez de alzada indagar sobre los hechos, con la finalidad de emitir resoluciones más correctas, quitándole el papel de un mero espectador; ${ }^{19}$ esto no significa que en la función de juzgar se actúe parcialmente, sino que en uso de sus potestades, puede hacerse llegar de mayor información antes de decidir sobre las pretensiones de las partes.

En materia electoral, la sentencia del SUP-JRC-052/98, en forma abierta la Sala Superior del TEPJF precisó que "procede la realización de diligencias para mejor proveer, cuando en autos falten elementos suficientemente ilustrativos para dirimir la contienda, caso en el cual, la autoridad sustanciadora del medio de impugnación relativo, debe recabar toda aquella información que amplíe el campo de análisis de los hechos controvertidos, por ejemplo, los paquetes electorales cuya votación se cuestiona, pero debe de abstenerse de hacerlo respecto de aquéllos que no sean objeto de la contienda", es decir, el juzgador puede llevar al proceso medios de prueba, mas no hechos.

\footnotetext{
18 Memorias del VIII Congreso Mexicano de Derecho Procesal, México, 1980, visible en la siguiente dirección electrónica http://www.eumed.net/librosgratis/2011c/1003/principios tecnicos.html. Consulta realizada el 15 de marzo de 2014.

19 Así el artículo 324, establece: No obstante, lo dispuesto en el artículo anterior, si después de celebrada la vista el tribunal creyere necesario la práctica de alguna diligencia para ilustrar su criterio, podrá decretarla para mejor proveer y la practicará dentro de los diez días siguientes, con arreglo a las disposiciones relativas de este Código. Practicada que fuere, fallará el asunto dentro de los cinco días siguientes.
} 


\section{La congruencia legal, el protagonismo judicial y resoluciones ultra petita.}

El Artículo 407 del Código Nacional de Procedimientos Penales, se refiere al principio de congruencia en las sentencias, consistente en que la sentencia de condena no podrá sobrepasar los hechos probados en juicio. En el apartado de apelación se norma la prohibición de resolver ultra petita..$^{20}$

Llama fuertemente la atención la tesis disímbola que destaca la corrección a la acusación con afectación del sentenciado, por parte del Segundo Tribunal Colegiado en Materia Penal y Administrativa del Quinto Circuito, bajo el epígrafe INDIVIDUALIZACIÓN DE LAS PENAS. LA DETERMINACIÓN DEL TRIBUNAL DE ALZADA DE ATENDER PARA SU FIJACIÓN, A FACTORES DESFAVORABLES AL CONDENADO ACREDITADOS EN EL PROCESO, AUN CUANDO ÉSTOS NO HAYAN SIDO HECHOS VALER POR EL MINISTERIO PÚBLICO EN LAS CONCLUSIONES ACUSATORIAS, NO ES VIOLATORIA DE GARANTÍAS.

En la reforma al artículo 314 del Código de Procedimientos Penales para el Distrito Federal, ${ }^{21}$ se dispuso en el mismo sentido que según las circunstancias que aprecie el Juez en la instancia podrá, de oficio, ordenar el desahogo de las pruebas que a su juicio considere necesarias para mejor proveer, o bien ampliar el plazo de su desahogo hasta por cinco días más.

El juez no solo debe enfocarse a desahogar pruebas, ampliar plazos, o reclasificar el delito, a mi juicio también debe aplicar normas que incluso no le estén destinadas, para agilizar la administración de justicia; por ejemplo en el sistema penal tradicional al juez de primera instancia le está vedado decretar la libertad de sentenciado cuando se le haya aplicado una pena menor de 5 años y el Ministerio Publico haya apelado, ${ }^{22}$ sin embargo en segunda instancia el Tribunal si podía otorgársela en virtud de la jurisprudencia por contradicción de tesis visible al rubro LIBERTAD CAUCIONAL (APELACIÓN EN MATERIA PENAL), identificada al índice como Tesis 470, Apéndice 1917-Septiembre 2011, Octava Época, Primera

20 Artículo 461 del CNPP

21 Publicado en el D.O.F. el 30 de septiembre de 1999.

22 A respecto el artículo 308 del CPPEN, establecía: Artículo 308.- Son apelables en ambos efectos solamente las sentencias definitivas en que se impugna alguna sanción. 
Sala, Tomo III, Penal Primera Parte - SCJN Sección - Adjetivo, p. 433. ${ }^{23} \mathrm{Si}$ bien la jurisprudencia obligatoria va destinada al Tribunal de apelación ¿porque entonces esperar a que llegue el caso al Tribunal para que sea éste quien deba otorgue la libertad?

Pero la congruencia en stricto sensu con algunas actividades judiciales totalmente aceptadas; si nos preguntáramos cual sujeto del procedimiento penal es quién impone las penas, responderíamos que la imposición de las penas, su modificación y duración son propias y exclusivas de la autoridad judicial, pues así lo preceptúa el tercer párrafo del artículo 21 de la CPEUM.

En efecto, imponer significa poner una carga, una obligación u otra cosa, ${ }^{24}$ que aplicado a la facultad de punir, significa que es el juez penal es quien cuenta de forma exclusiva con la atribución de imponer las penas o sanciones, sean cual fuere su categoría. Por otro lado, pretender, significa hacer diligencias para conseguir algo; ${ }^{25}$ por tanto la solicitud del Ministerio Publico está sujeta a eso, solo el pretender la imposición de una pena, mas no el imponerse ante el órgano jurisdiccional, limitándolo a no imponer una sanción mayor a la que éste solicitada. ${ }^{26}$

¿Cómo podrá entonces, el juzgador sortear esta encomienda constitucional propia y exclusiva, cuando la parte acusadora es quien le fija el quantum de la pena, ${ }^{27}$ si por mucho se ha dicho que no puede ir mas allá de lo solicitado por las

$23 \mathrm{Al}$ imponerse una pena que no excede de cinco años, procede la libertad bajo fianza de los quejosos, la que debe conceder el juzgador de segundo grado, por tener jurisdicción y satisfacer los requisitos legales. No obsta que, por procesarse a los acusados por delito cuyo término medio aritmético supera los cinco años de prisión; se encuentre subjúdice la sentencia que impuso pena menor a dicho término, y que hayan apelado tanto el reo como el Ministerio Público, puesto que para conceder la libertad caucional, ha de considerarse la situación de los inculpados originada por la pena impuesta en la primera instancia, de menos de cinco años de prisión, y que la garantía constitucional no puede ignorarse por el posible aumento de la sanción, al resolverse la apelación del órgano acusador, máxime que se prejuzgaría la decisión de la alzada. La finalidad del legislador al conceder tal beneficio, obviamente es la de proporcionar que los acusados gocen de libertad caucional, para que no sufran prisión preventiva, en caso de ser inocentes.

24 Real Academia Española, http://dle.rae.es/?id=L5LrGP0. Consulta realizada el 23 de mayo de 2017. 25 Real Academia Española, http://dle.rae.es/?id=U86gASi. Consulta realizada el 23 de mayo de 2017.

26 El segundo párrafo del artículo 206 del CNPP, establece que no podrá imponerse una pena distinta o de mayor alcance a la que fue solicitada por el Ministerio Público y aceptada por el acusado.

27 Es precisamente en la acusación, el momento en el que el Ministerio Publico expone su pretensión de viva voz, solicitado el quantum de la pena, véase el artículo 335 fracción IX del CNPP. 
partes atento al principio de congruencia que rige en el sistema penal acusatorio oral? ¿Por qué se le impide al juzgador valorar libremente las circunstancias agravantes o atenuantes del caso concreto establecidas en el CPEN, mediante la solicitud de pena o medida de seguridad hecha por el Ministerio Público? ${ }^{28}$ ¿Tiene algún caso la existencia de figuras que atenúan a agravan la pena, tales como: ¿La tentativa, ${ }^{29}$ la calidad específica del autor, el concurso real e ideal, ${ }^{30}$ la reincidencia, la pluralidad de sujetos, las circunstancias de tiempo, modo y lugar, entre otras, si el pedimento ministerial es el que marca el parámetro de la imposición de la pena?

Ante el límite establecido, el juzgador previo pedimento ministerial, no puede imponerle una pena más allá del máximo solicitado, y en su caso, solo le está facultado imponer una pena menor valiéndose de las circunstancias atenuantes, lo que incluso abre la puerta para una posible revisión por parte del Tribunal. ¿Acaso el Ministerio Público ha creado un sistema de punibilidad distinto al establecido para el juez y prevalece finalmente, dándole la vuelta a lo mandatado en la Carta Magna? ¿De quién entonces es la atribución de aumentar o disminuir las penas en los delitos y porqué otro poder se inmiscuye en dicha función?

Lo mismo ocurre en cuanto la aplicación de las medidas cautelares, las cuales el juez no podrá aplicar alguna más grave que la solicitada por el Ministerio Público, si podrá combinarlas, pero en ningún caso podrá rebasar la solicitud. ${ }^{31}$

También se deja de ver otra incongruencia de normas penales, cuando se actualiza la autoría indeterminada prevista en la fracción VIII del artículo 17 del CPEN, relativa a que no consta quién de los participantes del ilícito produjo el resultado final (responsabilidad correspectiva), el Juez debe imponer las

28 Fracción XXI del artículo 131 del CNPP.

29 El artículo 100 del CNPEN, estipula que al responsable de tentativa se le aplicará de tres meses hasta las tres cuartas partes del máximo de la sanción señalada en la ley al delito que el agente pretendió realizar.

30 El artículo 101 del CNPEN establece al respecto: En caso de concurso real se impondrá la sanción correspondiente al delito que merezca pena mayor, la que podrá aumentarse hasta la suma de las sanciones de los demás delitos, sin que pueda exceder de sesenta años. El artículo 102 de la propia legislación señala: En caso de concurso ideal, se aplicará la sanción correspondiente al delito que merezca pena mayor, la que podrá ser aumentada hasta una mitad más de los demás delitos cometidos, sin que pueda exceder de sesenta años.

31 Véase el artículo 157 del CNPP. 
penas tomando en cuenta el diverso artículo 69 del CPEN, que señala que en la autoría indeterminada se impondrán hasta las tres cuartas partes de las sanciones previstas para el delito de que se trate; de ahí que deba realizar la operación aritmética correspondiente para precisar a cuánto equivalen las tres cuartas partes de las penas mínimas y máximas y, partiendo de dichas cantidades, y del grado de culpabilidad del sentenciado, determinar la sanción aplicable, ${ }^{32}$ pero solo determinarla, mas no imponerla hasta en tanto una de las partes sea el que la precise, a menos que como ya se dijo sea menor.

Es en esta etapa del delito que la teoría penal analítica a denominado culpabilidad, (Orellana, 2003: 8) donde el juez penal se sitúa en la mente del individuo imputado, a efecto de valorar libremente (no supeditado al Ministerio Público) si le es reprochable su conducta, si le ha de aplicar una pena por haber actuado de forma distinta a la esperada por la sociedad, y en su caso si le era exigible comprender la antijuridicidad. (Zaffaroni, 1994: 544)

En segunda instancia se sigue la misma suerte, ya que está prohibido modificar la sanción en perjuicio, cuando el recurso ha sido interpuesto sólo por el imputado o su Defensor, ${ }^{33}$ esto es, no se le impondrá una sanción superior a la impuesta en la sentencia de primer grado, la cual llega limitada por la solicitud del representante social y cuyas agravantes no pueden ser estudiadas por el órgano colegiado.

En cuanto a la pena por reparación del daño, que constituye el objeto del proceso penal, ${ }^{34}$ como una actividad jurisdiccional podrá considerarse que el juez de control podrá revisar, actualizar o enmendar el error del Ministerio Público referente a éste derecho fundamental, ya que atendiendo a los hechos y a las

32 Véase la tesis jurisprudencial identificada al rubro como INDIVIDUALIZACIÓN DE LA PENA EN LOS DELITOS EN QUE SE ACTUALIZA LA AUTORÍA INDETERMINADA. PARA ESTABLECERLA, EL JUEZ DEBE REALIZAR LA OPERACIÓN MATEMÁTICA CORRESPONDIENTE PARA PRECISAR A CUÁNTO EQUIVALEN LAS TRES CUARTAS PARTES DE LAS PENAS MÍNIMAS Y MÁXIMAS Y, PARTIENDO DE DICHAS CANTIDADES Y DEL GRADO DE CULPABILIDAD DEL SENTENCIADO, SEÑALAR LA SANCIÓN APLICABLE (LEGISLACIÓN DEL ESTADO DE GUERRERO). Tesis: XXI.1o.P.A. J/2 (10a.), Gaceta del Semanario Judicial de la Federación, Décima Época, Tribunales Colegiados de Circuito, Libro 6, mayo de 2014, Tomo III, Pag. 1625 Jurisprudencia(Penal) 33 Artículo 462 del CNPP.

34 El artículo 20 fracción I Apartado A, señala que el proceso penal tendrá por objeto el esclarecimiento de los hechos, proteger al inocente, procurar que el culpable no quede impune y que los daños causados por el delito se reparen. (las negritas son mías) 
pretensiones de las partes, podrá concluir que la cantidad establecida por ese concepto, se encuentra desajustada con las medios de prueba y la realidad; de ahí que mediante una decisión racional por auto o sentencia, puede decidir que el monto reparatorio debe ser mayor al pretendido y pedido, esto es puede ir más allá de lo pedido por los sujetos o las partes, pudiendo apoyarse en que no se estimaron los salarios o percepciones correspondientes, ni los gastos por causa de incapacidad temporal de la víctima, entre otros. ${ }^{35}$

En el mismo sentido, el penúltimo párrafo del artículo 316 del CNPP, faculta al Juez de Control para otorgarle a los hechos motivo de la imputación, una clasificación jurídica distinta a la asignada por el Ministerio Público, fijando así el auto de vinculación, por el que forzosamente se seguirá el proceso. Al existir homogeneidad, en el bien jurídico, en los sujetos activo y pasivo, en el objeto del delito, así como en los hechos motivos de la imputación, el Juez podrá aplicar medidas cautelares o penas más graves, si el delito así lo especifica o bien por sus calificativas.

Como se observa, el Juez rompe de esta manera con el principio de congruencia, alterando el fundamento de la pretensión, al asumir una postura discrecional y activa, corrigiendo el error de Ministerio Publico, anteponiendo el razonamiento judicial con el propósito de lograr el equilibrio entre los hechos imputados y el ordenamiento jurídico que a su juicio considera corresponden a la litis, lo cual no necesariamente debe considerarse una dictadura judicial, como se refiere el principio de congruencia, sino que hace efectivo el principio de legalidad, al gozar de plenitud y arbitrio judicial.

Respecto a la norma que extiende una resolución que favorece a otros autores y partícipes del delito, se trata de una resolución de segunda instancia que beneficia a los coimputados que no apelaron, siempre y cuando se encuentren en los supuestos que se establece la norma. Al hablar de una resolución favorable, se entiende que existe la prohibición de reformarla en perjuicio del recurrente y de extender los efectos desfavorables a los demás. ${ }^{36}$

35 Tomar en cuenta inclusive el proyecto de vida de la víctima, por ejemplo, si se trataba de un estudiante destacado o de un científico.

36 El segundo párrafo del artículo 461 del CNPP, que señala: Si sólo uno de varios imputados por el mismo delito interpusiera algún recurso contra una resolución, la decisión favorable que se dictare aprovechará a los 
Indudablemente esta fórmula constituye un verdadero reto para el tribunal que resolverá el recurso, ya sea que el recurrente obtenga una sentencia favorable al no acreditarse los elementos del tipo penal de que se trate ${ }^{37}$ que pueda beneficiar a los demás coimputados que no recurrieron, o bien que se dicte la nulidad de actuaciones que ordene reponer el procedimiento y que puede realmente considerarse que dicha resolución le es favorable al apelante, para que tenga efectos extensivos sobre los demás.

En otro supuesto, se analizamos el control de legalidad de la detención, el juez podrá reclasificar la hipótesis detención en flagrancia, cuando de forma errónea el Ministerio Publico haya señalado una hipótesis diferente a las catalogadas en el artículo 146 del CNPP, por ejemplo que el representante social especifique que el imputado fue detenido al estar cometiendo el hecho y de la exposición de los hechos se desprenda que fue detenido inmediatamente después de cometido el hecho.

En el mismo sentido el juez de control deberá suplir la deficiencia respecto a las calificativas que no le fueron expuestas por parte de la representación social, sea que por olvido en cuanto a su exposición, falta de fundamentación, en cuanto a la cuantía, o la gravedad del delito.

En cuanto al procedimiento abreviado ¿Una vez dictado el auto de vinculación a proceso o antes de la emisión del auto de apertura a juicio oral, ya no tendrá cabida el procedimiento abreviado? ${ }^{38}$ el CNPP no refiere nada sobre este tema, se puede considerar que al juez, dentro de sus funciones, deberá permitir en cualquier audiencia posterior al auto de apertura a juicio, ya que independientemente de las pruebas que se tengan que desahogar o desahogadas las mismas, el propósito del procedimiento abreviado consistente en darle solución al conflicto. El caso se complica ante la situación de que haya dos o más coimputados en un mismo hecho y uno de ellos solicite el procedimiento

demás, a menos que los fundamentos fueren exclusivamente personales del recurrente.

37 El penúltimo párrafo del artículo 406 del CNPP establece: La sentencia condenatoria hará referencia a los elementos objetivos, subjetivos y normativos del tipo penal correspondiente, precisando si el tipo penal se consumó o se realizó en grado de tentativa, así como la forma en que el sujeto activo haya intervenido para la realización del tipo, según se trate de alguna forma de autoría o de participación, y la naturaleza dolosa o culposa de la conducta típica.

38 Según lo dispone el artículo 202 del CNPP. 
abreviado y otro quisiera el enjuiciamiento hasta escuchar sentencia que pudiese ser absolutoria o condenatoria; por lo que el proceder del juzgador deberá permitirle ambas situaciones y en el caso de absolución deberá absolver también al procesado por el abreviado, si el caso así lo permite.

\section{Conclusiones}

La figura procesal ultra petita, se había encontrado vedado en la doctrina jurídica y en la ley, indicándole al juez que no se alejara de las pretensiones hechas por las partes, para no afectar con ello el principio de congruencia, debiendo resolver conforme a lo pedido, sin excederse, sin dejar de pronunciarse y no conceder menos de lo solicitado.

Sin embargo, con la reforma al artículo $1^{\circ}$ de la CPEUM del que derivan principios protectores de derechos humanos, se puede considerar, le permite al órgano jurisdiccional ejercer un verdadero control del proceso penal, a decidir libremente la imposición de las penas y a realizar actos tendientes al esclarecimiento de los hechos, proteger al inocente procurar que el culpable no quede impune, y que se repare el daño, con base en una verdadera investigación de los hechos y en las pruebas aportadas.

Para lo anterior, debe emitir sentencia declarativas e interpretativas y en algunos casos apartarse de lo estipulado en las normas, a fin de proteger los derechos fundamentales y emitir resoluciones no pedidas por las partes, sea para salvaguardar los derechos del niño, extender su resolución en favor de un coimputado no apelante, o bien de oficio corregir la sanción por reparación del daño ante un error del fiscal en cuanto a su cálculo, lo que también debe prevalecer en segunda instancia e incluso en ejecución de sentencias; sin que ello deba considerarse incongruencia ya que ante el error incluso inadvertido, debe existir algún medio de solución; lo anterior como único fin de dictar sentencias con justicia.

El órgano jurisdiccional, no debe limitarse a ser un mero espectador sometido a la voluntad de los sujetos antagónicos, sino que debe tomar la directriz 
del procedimiento penal, investigando los hechos e imponiendo la sanción que considere justa, siempre dentro del margen de punibilidad y, como un poder más del Estado, mediante sus resoluciones, ser capaz de cambiar los aspectos sociales, políticos y económicos, marcando también el rumbo nacional en concordancia y armonía con la Constitución Política de los Estados Unidos Mexicanos.

\section{Bibliografía}

DÍAZ DE LEÓN, Marco Antonio, "Diccionario de derecho procesal penal y de los términos usuales en el proceso penal, $2^{\mathrm{a}}$ ed., México, Porrúa, 1989, t. II.

FIX ZAMUDIO, Héctor, El Poder Judicial, Revista Jurídica UNAM, México, Instituto de Investigaciones Jurídicas, Serie Doctrina Jurídica, num. 3, 1999.

MANILI Pablo Luis, Marbury vs Madison, Reflexiones sobre una sentencia bicentenaria, s.e. ed. Porrúa, México 2011.

MARTÍNEZ, Fernando Rey, Reflexiones sobre una sentencia bicentenaria, ed. Porrúa, México 2011, s.e. p. XIII.

ORELLANA WIARCO, Octavio A. "Teoría del delito sistema causalista, finalista y funcionalista” 13 edición, México, Porrúa, 2003.

ZAFFARONI, Eugenio Raúl, Manual de derecho penal parte general, México, Cárdenas editor, segunda reimpresión 1994.

ZAGREBELSKY, Gustavo, El derecho dúctil, Editorial Trotta, octava edición, España, 2008

Constitución Política de los Estados Unidos Mexicanos", Leyes y Códigos de México, 170ª ed, México, Porrúa, 2013.

Ley de Amparo vigente, publicada en el Diario Oficial de la Federación de fecha 2 de abril de 2013.

Código Penal para el Estado de Nayarit.

Código Nacional de Procedimientos Penales.

Ley Federal del Trabajo, publicada en el Diario Oficial de la Federación el $1^{\circ}$ de abril de 1970 . 
Ley Orgánica del Poder Judicial para el Estado de Nayarit, publicada el día 20 de marzo de 2010, en el Periódico Oficial, Órgano del Gobierno del Estado de Nayarit.

Jurisprudencia de la SCJN.

Diccionario jurídico ESPASA, (e) siglo XXI, s.e. España, Espasa Calpe S.A., 2002. 